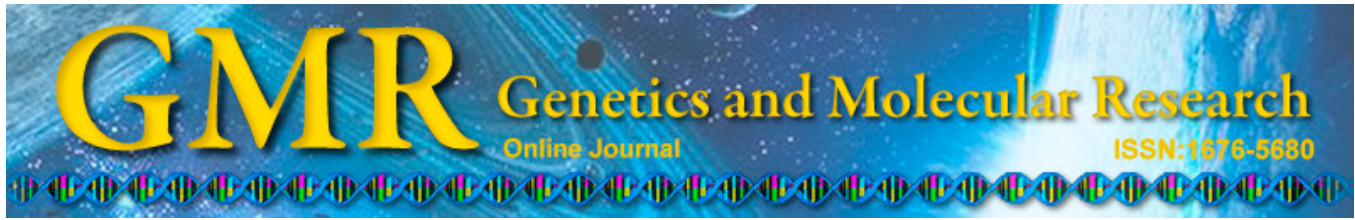

\title{
IL-8 -251T/A polymorphism is associated with susceptibility to acute pancreatitis
}

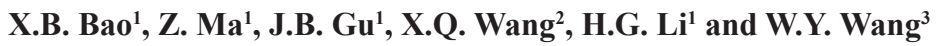 \\ ${ }^{1}$ Department of General Surgery, Henan Provincial People's Hospital, \\ People's Hospital of Zhengzhou University, Zhengzhou, China \\ ${ }^{2}$ Digestive System Department, Henan Provincial People's Hospital, \\ People's Hospital of Zhengzhou University, Zhengzhou, China \\ ${ }^{3}$ Department of Medical Oncology, Henan Provincial People's Hospital, \\ People's Hospital of Zhengzhou University, Zhengzhou, China \\ Corresponding author: X.B. Bao \\ E-mail: hepingxiang96@163.com \\ Genet. Mol. Res. 14 (1): 1508-1514 (2015) \\ Received April 25, 2014 \\ Accepted October 22, 2014 \\ Published February 20, 2015 \\ DOI http://dx.doi.org/10.4238/2015.February.20.6
}

\begin{abstract}
We conducted a case-control study to clarify the associations between inflammatory cytokine, including interleukin (IL)-1b, IL-6, IL-8, and IL-10, polymorphisms and risk of acute pancreatitis. Genotyping analyses of $I L-1 \beta+3954 \mathrm{C} / \mathrm{T}$ (rs1143634), $I L-1 \beta-511 \mathrm{C} / \mathrm{T}$ (rs16944), IL-6 -174 G/C (rs1800795), IL-6 -634 C/G (rs1800796), $I L-8$-251T/A (rs4073), IL-10 -1082A/G (rs1800896), and $I L-10$ $-819 \mathrm{C} / \mathrm{T}$ (rs1800871) were conducted using polymerase chain reactionrestriction fragment length of polymorphism. Unconditional logistic regression analysis was utilized to assess the potential association between genotype frequencies and risk of acute pancreatitis. Multivariate regression analyses showed that subjects carrying the $I L-8-251 \mathrm{AA}$ genotype had a significantly increased risk of acute pancreatitis, with an adjusted odds ratio (95\% confidence interval) of $1.55(1.02-2.36)$. However, we found no significant association between $I L-1 \beta+3954$
\end{abstract}


$\mathrm{C} / \mathrm{T}, I L-1 \beta-511 \mathrm{C} / \mathrm{T}, I L-6-174 \mathrm{G} / \mathrm{C}, I L-6-174 \mathrm{G} / \mathrm{C}, I L-6-634 \mathrm{C} / \mathrm{G}$, $I L-10-1082 \mathrm{~A} / \mathrm{G}$, or $I L-10-819 \mathrm{C} / \mathrm{T}$ polymorphisms and risk of acute pancreatitis. We found that the $I L-8-251 \mathrm{~T} / \mathrm{A}$ polymorphism was associated with a higher susceptibility to acute pancreatitis in a Chinese population.

Key words: Acute pancreatitis; Inflammatory cytokines; Polymorphism

\section{INTRODUCTION}

Acute pancreatitis (AP) is a common and potentially morbid disease with a highly variable clinical course with an estimated incidence of approximately $10-30 / 10^{5}$ individuals worldwide (Eland et al., 2000; Andersson et al., 2004; Goldacre and Roberts, 2004; Gislason et al., 2004). The clinical course of AP typically shows minimal organ dysfunction that recovers within several days, but some patients may experience a severe attack involving organ failure and severe complications as well as a high mortality rate (Neoptolemos et al., 1998; Lankisch et al., 2003; Swaroop et al., 2004). Two factors known to cause AP include alcohol and gallstones, which play different roles in pathogenic mechanisms to cause pancreatic acinar cell damage and thus induce AP (Dufour and Adamson, 2003; Venneman et al., 2005). Alcohol abuse is the most common cause of AP in men, while gallstone migration into the bile duct is the main cause of AP in women (Dufour and Adamson, 2003). However, the detailed etiology underlying AP remains unclear. Previous studies showed that inflammatory cytokines are important risk factors of AP (Gu et al., 2013; Yin et al., 2013; Wang et al., 2014).

Interleukin (IL) is a member of the inflammatory cytokine family and plays an important role in the inflammatory response and in immune system regulation. Previous studies have shown that enhanced secretion of IL-1b, IL-6, IL-8, and IL-10 may promote the pathological development of AP (de Beaux et al., 1996; Berney et al., 1999; Chen et al., 1999; Hirota et al., 2000). Serum levels of IL are regulated at the transcriptional level (Eskdale et al., 1998; Fishman et al., 1998; Brull et al., 2001; Nauck et al., 2002; Kilpinen et al., 2002; Taguchi et al., 2005; Ohyauchi et al., 2005). Recent clinical studies have shown that some polymorphisms in the IL promoter region, such as $I L-1 b+3954 \mathrm{C} / \mathrm{T}$ (rs1143634), IL-1b -511 C/T (rs16944), IL-6 -174 G/C (rs1800795), IL-6 -634 C/G (rs1800796), IL-8 -251 T/A (rs4073), IL-10 -1082 A/G (rs1800896), $I L-10-819$ C/T (rs1800871), and $I L-10-592$ C/A (rs1800872), were correlated with IL gene transcription and its secretion (Eskdale et al., 1998; Berney et al., 1999; Pooran et al., 2003). Therefore, coding differences in IL genes may play a role in the pathological development or severity of AP. Therefore, we conducted a case-control study to clarify the associations between polymorphisms in inflammatory cytokines such as IL-1b, IL-6, IL-8, and IL-10 and risk of AP.

\section{MATERIAL AND METHODS}

\section{Patients}

The diagnosis and evaluation of the severity of AP were made according to 
the following criteria: 1) abdominal pain characteristic of AP, 2) serum amylase and/ or lipase $\mathrm{C} 3$ times the upper limit of normal, and 3) characteristic findings of AP on computed tomography scan. A total of 335 patients were recruited after diagnosis of AP at the Second Affiliated Hospital of Anhui Medical University. Informed consent was obtained from patients or their relatives before enrolling in the study. In addition, 335 age-matched control subjects ( \pm 5 years) were recruited from individuals who attended our hospital for a routine health check-up. Each case and control was asked to provide $5 \mathrm{~mL}$ blood for DNA sequencing.

Written informed consent was obtained from all patients and controls before participating in the study. The protocol of our study was approved by the ethics board of the Second Affiliated Hospital of Anhui Medical University.

Patients were assessed upon enrollment into the study. Organ failure was defined when patients showed shock, pulmonary insufficiency, or renal failure.

\section{Genotyping analysis}

All study subjects were asked to provide $5 \mathrm{~mL}$ peripheral venous blood. According to the manufacturer instructions, genomic DNA was extracted from blood samples using the TIANamp blood DNA kit (Tiangen Biotech, Beijing, China). Genotyping analyses of $I L$ $1 \beta+3954 \mathrm{C} / \mathrm{T}$ (rs1143634), IL-1 $\beta$-511 C/T (rs16944), IL-6 -174 G/C (rs1800795), IL-6 -634 C/G (rs1800796), $I L-8$-251T/A (rs4073), $I L-10-1082 \mathrm{~A} / \mathrm{G}$ (rs1800896), and $I L-10-819 \mathrm{C} / \mathrm{T}$ (rs1800871) were conducted by polymerase chain reaction-restriction fragment length of polymorphism (PCR-RFLP). Primers and probes of $I L-1 \beta, I L-6, I L-8$, and $I L-10$ were designed using the Sequenom Assay Design 3.1 software according to manufacturer instructions (Sequenom, Inc., San Diego, CA, USA). The PCR was conducted in a 30- $\mu \mathrm{L}$ volume, which included $25 \mathrm{mM} \mathrm{MgCl}, 2 \mathrm{mM} 4 \mathrm{X}$ dNTPs, $20 \mu \mathrm{M}$ of each primer, and $5 \mathrm{U} / \mu \mathrm{L} \mathrm{Taq}$ DNA polymerase. The PCR was run at $94^{\circ} \mathrm{C}$ for 5 min, followed by 35 cycles of denaturation at $94^{\circ} \mathrm{C}$ for $45 \mathrm{~s}$, annealing at $62^{\circ} \mathrm{C}$ for $60 \mathrm{~s}$, and extension at $72^{\circ} \mathrm{C}$ for $60 \mathrm{~s}$, with a final extension at $72^{\circ} \mathrm{C}$ for $10 \mathrm{~min}$. For quality control, $5 \%$ of samples were randomly selected, and the results of repeated analysis showed $100 \%$ concordance.

\section{Statistical analysis}

Continuous variables are reported as means \pm standard deviation, while categorical variables are expressed as frequencies and percentages (\%). The $\chi^{2}$-test was used to determine whether the genotype distribution of the 3 single-nucleotide polymorphisms were in line with Hardy-Weinberg equilibrium among controls. Odds ratios (ORs) and corresponding 95\% confidence intervals (CIs) were calculated by unconditional logistic regression analysis and utilized to assess the potential association between genotypes frequencies and risk of AP. Homozygotes of the most frequent genotype were regarded as the reference group. All P values were 2-tailed, and differences were considered to be statistically significant when $\mathrm{P}<0.05$. SPSS statistical package, version 11.0 (SPSS Inc., Chicago, IL, USA) for Windows was used for statistical analyses. 


\section{RESULTS}

The distributions of general characteristics selected of study subjects are shown in Table 1. No significant differences were observed between the cases and controls for age and gender distribution. There were significant associations between cases and controls in terms of family history, tobacco smoking, and alcohol consumption $(\mathrm{P}<0.05)$.

\begin{tabular}{|c|c|c|c|c|c|}
\hline Indices & Cases & $\%$ & Control & $\%$ & $P$ value \\
\hline \multicolumn{6}{|l|}{ Gender } \\
\hline Male & 205 & 61.2 & 205 & 61.2 & - \\
\hline Female & 130 & 38.8 & 130 & 38.8 & 1.00 \\
\hline \multicolumn{6}{|l|}{ Age } \\
\hline$<60$ & 119 & 35.4 & 115 & 34.2 & - \\
\hline$\geq 60$ & 216 & 64.6 & 220 & 65.8 & 0.75 \\
\hline \multicolumn{6}{|c|}{ Family history } \\
\hline No & 296 & 88.3 & 326 & 97.4 & - \\
\hline Yes & 39 & 11.7 & 9 & 2.6 & $<0.001$ \\
\hline \multicolumn{6}{|c|}{ Tobacco smoking } \\
\hline Never & 230 & 68.6 & 253 & 75.4 & - \\
\hline Yes & 105 & 31.4 & 82 & 24.6 & 0.048 \\
\hline \multicolumn{6}{|c|}{ Alcohol consumption } \\
\hline Never & 172 & 51.2 & 216 & 64.5 & - \\
\hline Yes & 163 & 48.8 & 119 & 35.5 & $<0.001$ \\
\hline
\end{tabular}

The observed genotype frequencies of $I L-1 \beta+3954 \mathrm{C} / \mathrm{T}$ (rs1143634), $I L-1 \beta-511 \mathrm{C} / \mathrm{T}$ (rs16944), IL-6 -174 G/C (rs1800795), IL-8 -251T/A (rs4073), IL-10 -1082A/G (rs1800896), and $I L-10-819 \mathrm{C} / \mathrm{T}$ (rs1800871) in 335 controls conformed to Hardy-Weinberg equilibrium (Table 2). However, $I L-6$-634 C/G (rs 1800796) genotype distributions deviated from HardyWeinberg equilibrium. We analyzed the differences between cases and controls to determine the distribution of genotypes.

Table 2. Genotype characteristics of the $I L-1 \beta, I L-6, I L-8$, and $I L-10$ polymorphisms.

\begin{tabular}{|c|c|c|c|c|c|}
\hline \multirow[t]{2}{*}{ Gene } & \multirow[t]{2}{*}{ SNP } & \multirow[t]{2}{*}{ Alleles } & \multicolumn{2}{|c|}{$\mathrm{MAF}^{1}$} & \multirow[t]{2}{*}{$\mathrm{HWE}^{2}$ (P value) in controls } \\
\hline & & & Control group & From dbSNP & \\
\hline$I L-1 \beta+3954 \mathrm{C} / \mathrm{T}$ & rs1143634 & $\mathrm{C} / \mathrm{T}$ & 0.196 & 0.1455 & 0.08 \\
\hline$I L-1 \beta-511 \mathrm{C} / \mathrm{T}$ & rs16944 & $\mathrm{G} / \mathrm{A}$ & 0.426 & 0.4651 & 0.099 \\
\hline$I L-6-174 \mathrm{G} / \mathrm{C}$ & rs 1800795 & $\mathrm{G} / \mathrm{C}$ & 0.207 & 0.1850 & 0.55 \\
\hline$I L-6-634 \mathrm{C} / \mathrm{G}$ & rs1800796 & $\mathrm{G} / \mathrm{C}$ & 0.292 & 0.2897 & 0.03 \\
\hline$I L-8-251 \mathrm{~T} / \mathrm{A}$ & rs4073 & $\mathrm{A} / \mathrm{T}$ & 0.470 & 0.4972 & 0.08 \\
\hline$I L-10-1082 \mathrm{~A} / \mathrm{G}$ & rs1800896 & $\mathrm{A} / \mathrm{G}$ & 0.299 & 0.3026 & 0.072 \\
\hline$I L-10-819 \mathrm{C} / \mathrm{T}$ & rs 1800871 & $\mathrm{C} / \mathrm{T}$ & 0.418 & 0.4086 & 0.18 \\
\hline
\end{tabular}

${ }^{1} \mathrm{MAF}$ : minor allele frequencies; ${ }^{2} \mathrm{HWE}$ : Hardy-Weinberg equilibrium.

Multivariate regression analyses showed that subjects carrying the $I L-8$-251 AA genotype had a significantly increased risk of AP, with adjusted ORs $(95 \% \mathrm{CI})$ of $1.55(1.02-2.36)$ (Table 3). However, we did not observe a significant association between $I L-1 \beta+3954 \mathrm{C} / \mathrm{T}$, $I L-1 \beta-511 \mathrm{C} / \mathrm{T}, I L-6-174 \mathrm{G} / \mathrm{C}, I L-6-174 \mathrm{G} / \mathrm{C}, I L-6-634 \mathrm{C} / \mathrm{G}, I L-10-1082 \mathrm{~A} / \mathrm{G}$, or $I L-10$ $-819 \mathrm{C} / \mathrm{T}$ polymorphisms and risk of AP. 
Table 3. Association between polymorphisms of $I L-1 \beta, I L-6, I L-8$, and $I L-10$ polymorphisms and AP risk.

\begin{tabular}{|c|c|c|c|c|c|c|c|}
\hline \multirow[t]{2}{*}{ SNPs } & & \multirow{2}{*}{$\frac{\text { Cases }}{\mathrm{N}=335}$} & \multirow[t]{2}{*}{$\%$} & Controls & \multirow[t]{2}{*}{$\%$} & \multirow[t]{2}{*}{ Adjusted OR $(95 \% \mathrm{CI})^{1}$} & \multirow[t]{2}{*}{ Pvalue } \\
\hline & & & & $\mathrm{N}=335$ & & & \\
\hline \multirow[t]{3}{*}{$I L-1 \beta+3954 \mathrm{C} / \mathrm{T}$} & $\mathrm{CC}$ & 212 & 63.4 & 222 & 66.2 & 1.0 (Ref.) & - \\
\hline & $\mathrm{CT}$ & 99 & 29.68 & 95 & 28.5 & $1.09(0.77-1.55)$ & 0.62 \\
\hline & $\mathrm{TT}$ & 23 & 6.92 & 18 & 5.3 & $1.34(0.67-2.71)$ & 0.37 \\
\hline \multirow[t]{3}{*}{$I L-1 \beta-511 \mathrm{C} / \mathrm{T}$} & GG & 105 & 31.4 & 118 & 35.1 & 1.0 (Ref.) & . \\
\hline & GA & 155 & 46.2 & 149 & 44.6 & $1.17(0.81-1.68)$ & 0.38 \\
\hline & AA & 75 & 22.4 & 68 & 20.3 & $1.57(1.01-2.41)$ & 0.03 \\
\hline \multirow[t]{3}{*}{$I L-6-174 \mathrm{G} / \mathrm{C}$} & GG & 202 & 60.3 & 213 & 63.6 & 1.0 (Ref.) & - \\
\hline & $\mathrm{GC}$ & 109 & 32.5 & 106 & 31.5 & $1.09(0.77-1.53)$ & 0.63 \\
\hline & $\mathrm{CC}$ & 24 & 7.2 & 16 & 4.9 & $1.58(0.78-3.28)$ & 0.17 \\
\hline \multirow{3}{*}{$I L-6-634 \mathrm{C} / \mathrm{G}$} & GG & 163 & 48.6 & 176 & 52.6 & 1.0 (Ref.) & - \\
\hline & $\mathrm{GC}$ & 126 & 37.7 & 122 & 36.5 & $1.12(0.79-1.57)$ & 0.51 \\
\hline & $\mathrm{CC}$ & 46 & 13.7 & 37 & 10.9 & $1.34(0.81-2.24)$ & 0.23 \\
\hline \multirow[t]{3}{*}{$I L-8-251 \mathrm{~T} / \mathrm{A}$} & $\mathrm{TT}$ & 84 & 25.2 & 108 & 32.3 & 1.0 (Ref.) & 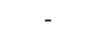 \\
\hline & TA & 144 & 43.1 & 139 & 41.4 & $1.33(0.91-1.96)$ & 0.13 \\
\hline & $\mathrm{AA}$ & 106 & 31.7 & 88 & 26.3 & $1.55(1.02-2.36)$ & 0.03 \\
\hline \multirow{3}{*}{$I L-10-1082 \mathrm{~A} / \mathrm{G}$} & $\mathrm{AA}$ & 163 & 48.6 & 176 & 52.4 & 1.0 (Ref.) & - \\
\hline & $\mathrm{AG}$ & 123 & 36.7 & 118 & 35.3 & $1.13(0.80-1.59)$ & 0.48 \\
\hline & GG & 49 & 14.7 & 41 & 12.3 & $1.29(0.79-2.12)$ & 0.28 \\
\hline \multirow[t]{3}{*}{$I L-10-819 \mathrm{C} / \mathrm{T}$} & $\mathrm{CC}$ & 115 & 34.2 & 123 & 36.7 & 1.0 (Ref.) & - \\
\hline & $\mathrm{CT}$ & 149 & 44.6 & 144 & 43.1 & $1.11(0.77-1.58)$ & 0.56 \\
\hline & $\mathrm{TT}$ & 71 & 21.2 & 68 & 20.2 & $1.12(0.72-1.73)$ & 0.61 \\
\hline
\end{tabular}

${ }^{1}$ Adjusted for gender, age, family history, tobacco smoking, and alcohol consumption.

\section{DISCUSSION}

In this current study, we investigated the role of $I L-1 \beta, I L-6, I L-8$, and $I L-10$ in the development of AP. This is the first study to examine the association between 7 single-nucleotide polymorphisms and AP risk. Our study showed that the $I L-8-251 \mathrm{~T} / \mathrm{A}$ polymorphism was associated with AP risk. Therefore, our findings identified single-nucleotide polymorphisms that influence gene function or expression and increase the risk of AP, which is valuable for predicting individual risk of AP and understanding the pathogenesis of developing AP.

It is known that the development of AP may be correlated with genetic polymorphisms. IL-8 is a well-known member of the inflammatory cytokine family. IL-8 shows potent chemotactic activity in neutrophils and plays a role in the activation of monocytes, macrophages, and lymphocytes (Mukaida et al., 1998). IL-8 is one of the earliest cytokines present in the serum of patients with AP; its persistently elevated levels can be used to assess the severity of AP (Pooran et al., 2003). IL-8 can become concentrated and activate neutrophilic leukocytes, which is important in the process of adult respiratory distress syndrome (Donnelly et al., 1993). A previous study showed that inhibiting the release of IL-8 can lower the severity and case fatality rate compared to inhibiting other inflammatory factors (Abe et al., 1995), suggesting that the $I L-8$ polymorphism may play a role in the development of AP.

Numerous previous studies have examined the role of IL-8 in the development of AP (Hofner et al., 2006; Chen, 2007; Tang et al., 2010). Tang et al. (2010) investigated the association between the $I L-8-251 \mathrm{~T} / \mathrm{A}$ polymorphism and risk of AP in a Chinese population and found that this polymorphism is involved in the development of AP. Hofner et al. (2006) conducted a study in Hungary and found that the $I L-8-251 \mathrm{~T} / \mathrm{A}$ heterozygote variant was present at a significantly higher frequency among patients with severe pancreatitis than among healthy blood donors. However, some studies reported inconsistent results. Chen and Nie (2008) conducted a case-control study to examine the relationship between the $I L-8-251 \mathrm{~T} / \mathrm{A}$ 
polymorphism and AP in a Han population and found no association between this gene polymorphism and risk of AP. In our study, we found that the $I L-8-251 \mathrm{~T} / \mathrm{A}$ polymorphism was associated with occurrence of AP. Discrepancies in population, case selection, and sample size may also have affected the results. Further studies are needed to determine the role of $I L-8$ polymorphisms in the risk of AP.

There were several limitations to our study. First, cases were selected from a single hospital, which may not be representative of the general population. Second, other genetic polymorphisms may influence the development of AP in addition to the $I L-8$ gene. Therefore, further multicenter studies with a larger sample including different ethnicities are needed to investigate the role of $I L-8-251 \mathrm{~T} / \mathrm{A}$ polymorphisms in the prognosis of AP.

In conclusion, we found that the $I L-8-251 \mathrm{~T} / \mathrm{A}$ polymorphism was associated with a higher susceptibility to AP in a Chinese population. However, we did not observe a significant association between the $I L-1 \beta, I L-6$, and $I L-10$ polymorphisms and risk of AP. Further studies are needed to confirm the clinical significance of these results.

\section{REFERENCES}

Abe R, Shimosegawa T, Kimura K, Abe T, et al. (1995). The role of endogenous glucocorticoids in rat experimental models of acute pancreatitis. Gastroenterology 109: 933-943.

Andersson R, Andersson B, Haraldsen P, Drewsen G, et al. (2004). Incidence, management and recurrence rate of acute pancreatitis. Scand. J. Gastroenterol. 39: 891-894.

Berney T, Gasche Y, Robert J, Jenny A, et al. (1999). Serum profiles of interleukin-6, interleukin-8, and interleukin-10 in patients with severe and mild acute pancreatitis. Pancreas 18: 371-377.

Brull DJ, Montgomery HE, Sanders J, Dhamrait S, et al. (2001). Interleukin-6 gene - $174 \mathrm{~g}>\mathrm{c}$ and $-572 \mathrm{~g}>\mathrm{c}$ promoter polymorphisms are strong predictors of plasma interleukin-6 levels after coronary artery bypass surgery. Arterioscler. Thromb. Vasc. Biol. 21: 1458-1463.

Chen CC, Wang SS, Lee FY, Chang FY, et al. (1999). Proinflammatory cytokines in early assessment of the prognosis of acute pancreatitis. Am. J. Gastroenterol. 94: 213-218.

Chen WC and Nie JS (2008). Genetic polymorphism of MCP-1-2518, IL-8-251 and susceptibility to acute pancreatitis: a pilot study in population of Suzhou, China. World J. Gastroenterol. 14: 5744-5748.

Chen XQ (2007). A study on the association between the interleukin- $1 \mathrm{~b}$, interleukin- 6 gene polymorphisms and the condition of patients with acute pancreatitis. Master's thesis, Fujian Medical University, Fujian, pp. 1-49.

de Beaux AC, Goldie AS, Ross JA, Carter DC, et al. (1996). Serum concentrations of inflammatory mediators related to organ failure in patients with acute pancreatitis. Br. J. Surg. 83: 349-353.

Donnelly SC, Strieter RM, Kunkel SL, Walz A, et al. (1993). Interleukin-8 and development of adult respiratory distress syndrome in at-risk patient groups. 341: 643-647.

Dufour MC and Adamson MD (2003). The epidemiology of alcohol-induced pancreatitis. Pancreas 27: 286-290.

Eland IA, Sturkenboom MJ, Wilson JH and Stricker BH (2000). Incidence and mortality of acute pancreatitis between 1985 and 1995. Scand. J. Gastroenterol. 35: 1110-1116.

Eskdale J, Gallagher G, Verweij CL, Keijsers V, et al. (1998). Interleukin 10 secretion in relation to human IL-10 locus haplotypes. Proc. Natl. Acad. Sci. USA 95: 9465-9470.

Fishman D, Faulds G, Jeffery R, Mohamed-Ali V, et al. (1998). The effect of novel polymorphisms in the interleukin-6 (IL-6) gene on IL-6 transcription and plasma IL-6 levels, and an association with systemic-onset juvenile chronic arthritis. J. Clin. Invest. 102: 1369-1376.

Gislason H, Horn A, Hoem D, Andrén-Sandberg A, et al. (2004). Acute pancreatitis in Bergen, Norway. A study on incidence, etiology and severity. Scand. J. Surg. 93: 29-33.

Goldacre MJ and Roberts SE (2004). Hospital admission for acute pancreatitis in an English population, 1963-98: database study of incidence and mortality. BMJ 328: 1466-1469.

$\mathrm{Gu}$ H, Werner J, Bergmann F, Whitcomb DC, et al. (2013). Necro-inflammatory response of pancreatic acinar cells in the pathogenesis of acute alcoholic pancreatitis. Cell Death Dis. 4: e816.

Hirota M, Nozawa F, Okabe A, Shibata M, et al. (2000). Relationship between plasma cytokine concentration and multiple organ failure in patients with acute pancreatitis. Pancreas 21: 141-146. 
Hofner P, Balog A, Gyulai Z and Farkas G, et al. (2006). Polymorphism in the IL-8 gene, but not in the TLR4 gene, increases the severity of acute pancreatitis. Pancreatology 6: 542-548.

Kilpinen S, Huhtala H and Hurme M (2002). The combination of the interleukin-1alpha (IL-1alpha-889) genotype and the interleukin-10 (IL-10 ATA) haplotype is associated with increased interleukin-10 (IL-10) plasma levels in healthy individuals. Eur. Cytokine Netw. 13: 66-71.

Lankisch PG, Blum T, Maisonneuve P and Lowenfels AB (2003). Severe acute pancreatitis: when to be concerned? Pancreatology 3: 102-110.

Mukaida N, Harada A and Matsushima K (1998). Interleukin-8 (IL-8) and monocyte chemotactic and activating factor (MCAF/MCP-1), chemokines essentially involved in inflammatory and immune reactions. Cytokine Growth Factor Rev. 9: 9-23.

Nauck M, Winkelmann BR, Hoffmann MM, Böhm BO, et al. (2002). The interleukin-6 G(-174)C promoter polymorphism in the LURIC cohort: no association with plasma interleukin-6, coronary artery disease, and myocardial infarction. J. Mol. Med. (Berl.) 80: 507-513.

Neoptolemos JP, Raraty M, Finch M and Sutton R (1998). Acute pancreatitis: the substantial human and financial costs. Gut 42: 886-891.

Ohyauchi M, Imatani A, Yonechi M, Asano N, et al. (2005). The polymorphism interleukin 8-251 A/T influences the susceptibility of Helicobacter pylori related gastric diseases in the Japanese population. Gut 54: 330-335.

Pooran N, Indaram A, Singh P and Bank S (2003). Cytokines (IL-6, IL-8, TNF): early and reliable predictors of severe acute pancreatitis. J. Clin. Gastroenterol. 37: 263-266.

Swaroop VS, Chari ST and Clain JE (2004). Severe acute pancreatitis. JAMA 291: 2865-2868.

Taguchi A, Ohmiya N, Shirai K, Mabuchi N, et al. (2005). Interleukin-8 promoter polymorphism increases the risk of atrophic gastritis and gastric cancer in Japan. Cancer Epidemiol. Biomarkers Prev. 14: 2487-2493.

Tang H, Liu CY, Wang XX, Li HY, et al. (2010). The relationship of interleukin-8 gene-251A/T polymorphism and acute pancreatitis. Prog. Mod. Biomed. 10: 3866-3868.

Venneman NG, Renooij W, Rehfeld JF, VanBerge-Henegouwen GP, et al. (2005). Small gallstones, preserved gallbladder motility, and fast crystallization are associated with pancreatitis. Hepatology 41: 738-746.

Wang XY, Tang QQ, Zhang JL, Fang MY, et al. (2014). Effect of SB203580 on pathologic change of pancreatic tissue and expression of TNF- $\alpha$ and IL-1 $\beta$ in rats with severe acute pancreatitis. Eur. Rev. Med. Pharmacol. Sci. 18: 338-343.

Yin YW, Sun QQ, Feng JQ, Hu AM, et al. (2013). Influence of interleukin gene polymorphisms on development of acute pancreatitis: a systematic review and meta-analysis. Mol. Biol. Rep. 40: 5931-541. 